\title{
Endometriyal Biopsi İşlemi Öncesinde Kullanılan Oral Hyosine N Butil Bromur’ün Analjezik Etkinliği
}

\author{
Analgesic Effect of Oral Hyoscine N Butyl Bromur in Endometrial Biopsy
}

\author{
Yeşim AKDEMIIR ${ }^{1}$, Görker SEL ${ }^{2}$, Büşra AYNALI ${ }^{2}$, Müge HARMA ${ }^{2}$, Mehmet İbrahim HARMA ${ }^{2}$
}

1. Zonguldak Bülent Ecevit Üniversitesi, Tip Fakültesi, Kadın Hastalıklarl ve Doğum AD., Zonguldak, Türkiye

2. Zonguldak Bülent Ecevit Üniversitesi, Tip Fakültesi, Zonguldak, Türkiye

\section{$\ddot{O Z Z E T}$}

Amaç: Bu çalışmanın amacı Pipelle ile yapılan endometrial biyopsi işlemi öncesinde oral yoldan alınan $10 \mathrm{mg}$ Hyosine $\mathrm{N} \mathrm{Bu}$ til Bromur (HBB)'nin analjezik etkinliğini de ğerlendirmektir.

Gereçler ve Yöntem: Eylül 2018- Eylül 2019 tarihleri arasında, Zonguldak Bülent Ecevit Üniversitesi'nde, anormal uterin kanamanın değerlendirilmesi için Pipelle ile endometriyal biyopsi yapılmış, 18-49 yaş arasındaki hastaların dosyaları retrospektif olarak incelendi. Endometriyal biyopsi işleminin 30 dakika öncesinde oral yoldan $10 \mathrm{mg} \mathrm{HBB}$ kullanan 48 hasta $H B B$ Grubu, endometriyal biyopsi işlemi öncesinde hiçbir analjezik kullanmayan 56 hasta ise Kontrol Grubu olarak ayrldd.

Bulgular: Yaş, vücut kitle indeksi, parite, vajinal ve sezaryen doğum sayısl, nulliparite, multiparite ve menopozal durum parametreleri açısından 2 grup arasında fark gözükmezken endometriyal biyopsinin hemen sonrasinda kaydedilmis VAS (0) ve endometriyal biyopsiden 30 dakika sonra kaydedilmis olan VAS (30) skorları HBB Grubunda Kontrol Grubuna göre daha düşük saptandl (sirastyla 59,3 $\pm 21,12$ vs 86,42 \pm 10.95 , ve 19,09 $\pm 23,85$ vs $55,71 \pm 21,67 ; p \leq 0,001)$.

Sonuç: Endometriyal biyopsi işleminden 30 dakika önce oral yoldan alınan $10 \mathrm{mg} H B B$ 'nin, endometriyal biyopsi strasinda ve işlemden 30 dakika sonrasında analjezik etkinliği vardır. Bu data HBB'nin diğer jinekolojik endikasyonlar ile kullanımının yaygınlaşmasına yardımcı olabilir.

Anahtar Kelimeler: ăgrı, hyosine $n$ butil bromur, pipelle, endometriyal biyopsi

\section{ABSTRACT}

Objective: To investigate the efficacy of oral $10 \mathrm{mg}$ Hyoscine $N$ Butyl Bromur (HBB) on pain perception of the patients who underwent endometrial biopsy with Pipelle.

Material and Methods: The charts of the patients who were 1849 years and underwent endometrial biopsy with Pipelle for evaluation of abnormal uterine bleeding at Zonguldak Bülent Ecevit University, between September 2018 and September 2019 were retrospectively evaluated. 48 patients were seperated as HBB Group who used oral $10 \mathrm{mg} H B B 30$ minutes before endometrial biopsy and 56 patients as Control Group who did not used any pain relief medication before endometrial biopsy.

\section{İletișim}

Sorumlu Yazar: Dr. Öğr. Üyesi, Yeşim AKDEMİR

Adres: Zonguldak Bülent Ecevit Üniversitesi Tıp Fakültesi, Kadın Hast. ve Doğum AD. 67600 Esenköy / Kozlu, Zonguldak, Türkiye Tel: +90 (505) 4970407 Fax: +90 (372) 2610155

E-Posta: yesimakdemir@yahoo.com

Makale Geliș: 20.09.2019

Makale Kabul: 26.10.2019

DOI: http://dx.doi.org/10.16948/zktipb.622227
Results: There were no statistically significant difference between two groups in age, BMI, parity, number of vaginal and cesarean births, nulliparity, multipartiy, and menopausal status. On the other hand, VAS (0) scores which were recorded immediately after endometrial biopsy and VAS (30) scores which were recorded 30 minutes after endometrial biopsy of the patients of the HBB Group were lower than the Control Group $(59,3 \pm 21,12$ vs $86,42 \pm 10.95$, ve $19,09 \pm 23,85$ vs $55,71 \pm$ $21,67$ respectively; $p \leq 0,001)$.

Conclusion: $10 \mathrm{mg}$ oral $\mathrm{HBB}$ when taken 30 minutes before intervention, significantly decreases pain associated with Pipelle endometrial biopsy. This data might help to increase the endication spectrum of HBB for analgesic purposes in gynecology field.

Keywords: endometrial biopsy, hyoscine n butyl bromur, pain, Pipelle

\section{GíRIŞ}

Endometriyal biyopsi anormal uterin kanama, postmenopozal kanama, infertilite, tekrarlayan gebelik kayb1 ve hormon replasman tedavilerinin cevabını değerlendirmede sık gerçekleştirilen bir girişimdir (1). Pipelle ile yapılan endometriyal biyopsi işlemi, tanısal doğruluğunun yüksek olup servikal dilatasyon gereksiniminin nadiren olması ile klasik dilatasyon küretaja göre daha sık kullanılan bir yöntem haline gelmiştir $(2,3)$. Pipelle ile endometriyal biyopsi ne kadar dilatasyon küretaja göre daha ağrısız bir işlem de olsa, hastalar serviksin tenakulum ile tutulmas1, Pipelle'in internal servikal ostan geçişi esnasında ağrı hissedebilmektedirler. Bu nedenle analjezi amaciyla; intrauterin anestezi, topikal analjezi, intrauterin anestezi ve nonsteroid antienflanmatuar ilaç (NSAID) kombinasyonu, oral NSAID, oral parasetamol gibi birçok ajan denenmiştir (4-7).

Hyosine N Butil Bromur (HBB) parasempatolitik etkileri olan semisentetik bir scopolamin derivesidir. Intraabdominal ve kadın genital organlarındaki parasempatetik gangliadaki kolinerjik transmisyonunu engelleyerek etkin anti-spasmotik etki gösterir. Biliyer kolik, renal kolik ve barsak spasmlarında, endoskopik girişimlerin öncesinde kullanılmaktadır. Kadın genital organlarında ise özellikle servikouterin pleksusda etkinliği gösterilmiştir (8). Bu özelliğinden ötürü, jinekolojide dismenorede, doğumda servikal dilatasyon amaciyla ve histerosalpingografi (HSG) öncesinde analjezi amacıyla HBB kullanılmış çalışmalar mevcuttur (9-12). Endometriyal biyopsi işlemi öncesinde ise HBB kullanımına dair bilgi kısıtlıdır. 
Çalışmamızın amacı endometrial biyopsi işlemi öncesinde oral yoldan alınan 10 mg HBB'nin analjezik etkinliğinin değerlendirmektir.

\section{GEREÇ ve YÖNTEM}

Zonguldak Bülent Ecevit Üniversitesi Etik Kurul'undan onay alındıktan sonra Eylül 2018 Eylül 2019 tarihleri arasında, Kadın Hastalıkları ve Doğum AD'da, anormal uterin kanamanın değerlendirilmesi için Pipelle ile endometriyal biyopsi yapılmış, 18 - 49 yaş arasındaki hastaların dosyaları retrospektif olarak incelendi. İşlem öncesinde HBB dişında ek analjezik kullanan, mevcut anksiyete ya da depresyon tanısı ile ilaç kullanımı olan, aktif genital enfeksiyonu bulunan, daha öncesinde servikal cerrahi geçirmiş olan, işlem sırasında servikal dilatasyon gereksinimi bulunan ve dosyalarında Vizuel Analog Skala (VAS) ile ağrı skorlama kaydı bulunmayan hastaların dosyaları inceleme dışı tutuldu.

Endometriyal biyopsi işleminin 30 dakika öncesinde oral yoldan $10 \mathrm{mg}$ HBB (Buscopan $10 \mathrm{mg}$ draje, Boehringer Ingelheim İlaç Ticaret A.Ş, Almanya) kullanan 48 hasta çalışma grubu, endometriyal biyopsi işlemi öncesinde hiçbir analjezik kullanmayan 56 hasta ise kontrol grubu olarak ayrildı. Hastaların demografik özellikleri, obstetrik hikayeleri ve endometriyal biyopsi işleminin hemen sonrasında ve 30 dakika sonrasındaki VAS ağrı skorları dosyalardan edinildi.

Çalışmanın istatistikleri SPSS 19.0 paket programında yapılmıştır. Nitel değişkenlere ait tanımlayıcı istatistikler frekans ve yüzde ile,nicel değişkenler aritmetik ortalama, medyan, minimum ve maksimum değerleriyle verilmiştir. Sürekli değişkenlerin normal dağılıma uygunluğu Shapiro Wilk testi ile değerlendirilmiştir. Normal dağılım göstermeyen nicel değişkenlerin 2 grup arası karşılaştırmalarında Mann Whitney U testi kullanılmıştır. Nitel değişkenlerin gruplar arası karşılaştırmalarında Yates ki-kare testi kullanılmıştır. Çalışmadaki tüm istatistiksel analizlerde $p$ değeri 0,05 in altındaki sonuçlar istatistiksel olarak anlamlı kabul edilmiştir.

Tablo 1: Grupların Karakteristikleri ve VAS Skorları.

\begin{tabular}{|c|c|c|c|}
\hline & $\begin{array}{l}\text { Buscopan } \\
\mathrm{N}=48\end{array}$ & $\begin{array}{l}\text { Kontrol } \\
\mathrm{N}=56\end{array}$ & $\mathrm{p} \#$ \\
\hline Yaş* & $45.56 \pm 13.34$ & $46,71 \pm 7.52$ & 0.45 \\
\hline VKİं* & $28.98 \pm 4.09$ & $32.05 \pm 4.43$ & 0,98 \\
\hline Parite* & $2.62 \pm 1.45$ & $2.50 \pm 1.34$ & 0,651 \\
\hline Vajinal doğum (n)* & $2.18 \pm 1.72$ & $2.03 \pm 1.68$ & 0,727 \\
\hline $\begin{array}{r}\text { Önceki sezaryen (n) } \\
\text { yok } \\
1 \\
2\end{array}$ & $\begin{array}{l}33 \\
9 \\
6\end{array}$ & $\begin{array}{l}38 \\
10 \\
8\end{array}$ & 0,985 \\
\hline Nullipar n(\%) & $12(25)$ & $14(25)$ & 1 \\
\hline Multipar n(\%) & $36(75)$ & $42(75)$ & 1 \\
\hline $\begin{array}{l}\text { Menopozal durum } \\
\text { Pre n(\%) } \\
\text { Post n(\%) }\end{array}$ & $\begin{array}{l}39(81.3) \\
9(18,8)\end{array}$ & $\begin{array}{l}24(42,9) \\
32(57,1)\end{array}$ & 0,31 \\
\hline $\operatorname{VAS}(0) *$ & $59,3 \pm 21,12$ & $86,42 \pm 10.95$ & $<0,001$ \\
\hline $\operatorname{VAS}(30) *$ & $19,09 \pm 23,85$ & $55,71 \pm 21,67$ & $<0,001$ \\
\hline
\end{tabular}

\section{BULGULAR}

HBB kullanmış 48 hastanın bulunduğu çalışma grubu ve hiç analjezik almamış 56 hastanın bulunduğu kontrol grubu karşılaştırıldı. Yaş, vücut kitle indeksi, parite, vajinal ve sezaryen doğum say1s1, nulliparite, multiparite ve menopozal durum parametreleri açısından 2 grup arasında fark gözükmezken endometriyal biyopsinin hemen sonrasinda kaydedilmiş VAS (0) ve endometriyal biyopsiden 30 dakika sonra kaydedilmiş olan VAS (30) skorları HBB grubunda kontrol grubuna göre daha düşük saptandi (sirasiyla $59,3 \pm 21,12$ vs $86,42 \pm 10.95$, ve $19,09 \pm 23,85$ vs $55,71 \pm 21,67 ; p \leq 0,001)$ (Tablo1).

\section{TARTIŞMA}

Çalışmamızın sonucunda endometriyal biyopsi öncesinde HBB kullanımının işlem sırasında hissedilen ağrı hissini azalttığını saptadık.

Endometriyal biyopsi her ne kadar minimal invaziv ve günübirlik bir girişim olsa da, işlem s1rasında hastalar orta-şiddetli seviyede ağrı hissetmekte ve işlem öncesinde analjezi gerekliliği ortaya çıkmaktadır (13). Bu amaçla sinirsel iletiyi azaltan veya bloke eden ajanlarla birçok çalışma yapılmıştır. Lokal bir anestetik olan lidokainin sprey, intrauterin ya da intraservikal krem, ve paraservikal blok enjeksiyonu olmak üzere çeşitli yollarla kullanıldı$\breve{g} 1$ çalışmalarda intrauterin lidokainin endometriyal biyopsi sırasındaki ağn hissini plaseboya göre anlamlı olarak azalttığı ve efektif olduğu saptanmıştır (14-18). Serviks ve alt uterusun ağr1 iletisi pelvik splanknik (S2-S4) ile taşınırken, fundus ve uterus ağrı iletisi hipogastrik sinirle alt torasik segmentle taşınması tek başına servikal anestezinin yetersizliğini açılayabilir.

Öte yandan rofekoksib, etorikoksib ve naproksen sodyum gibi NSAID'lerin analjezik etkinliğinin araştırıldığ 1 diğer çalışmalarda, tek başına kullanıldıklarında NSAID'lerin plaseboya göre anlamlı etkilerinin gözükmediği saptanmıştır $(4,19-21)$. Bununla beraber Doğan ve ark. işlem öncesi intauterin anestezi ve oral naproksen sodyum kombinasyonun analjezik etkinlik açısından yeterli olduğunu saptamışlardır (4). Ortaya çıkan sonuçlar endometriyal biyopsi sırasındaki ağrının sadece prostaglandinlerin açığa çıkışına bağlı olmadığını düşündürmektedir. Abbas ve ark. endometriyal biyopsi işlemi öncesinde uygulanan analjezik yöntemlerin değerlendirdikleri metaanalizde, işlemin hemen sonrasındaki ağrı hissinin azaltılması açısından lidokain sprey ve intrauterin lidokain kombinasyonu en etkili yöntem olduğu ayrıca lidokain ve naproksen sodyum kombinasyonun da analjezik etkinliğini göstermişlerdir (4).

Anti-spasmotikler jinekoloji alanında dismenore endikasyonuyla siklıkla kullanılmaktadırlar. Analjezik etkinliğinin gösterilmesi ile farklı alanlarda anti-spasmotik kulllanılabilirliği araştırılmıştır. HSG görüntülemesi sırasında oluşan ağrıyı önlemek için işlem öncesi HBB kullanımını inceleyen bir çalışmada Abbas ve ark. işlemden 30 dakika önce $20 \mathrm{mg}$ oral yoldan alınan HBB'nin analjezik etkinliğinin plaseboya üstün olmadığını göstermiş- 
tir (10). Diğer bir çalışmada ise HSG'dan 30 dakika önce $20 \mathrm{mg}$ İ.M yoldan uygulanan HBB'nin fallop tüplerinin spasmını azalttığı gösterilse de HSG görüntülemesi sırasında oluşan ağrıyı azaltmadığ 1 saptanmıştır (12). Benzer olarak Jareethum ve ark. salin infüzyon sonografi (SIS) öncesinde $10 \mathrm{mg}$ oral yoldan alınan HBB'nin analjezik etkinliğini gösterememişlerdir (11). HBB'nin analjezik etkinliğinin gösterilememesi, uterus duvarlarını ve tubaları mekanik olarak genişleten dolayısıyla ağrıya yol açan HSG ve SİS gibi işlemlerdeki ağriya yol açan mekanizmanın lokal prostaglandin üretimi ile ilişkili olabileceği ile açıklanabilir.

Karşit olarak HBB gibi bir anti-spasmotik olan drotaverin'in kullanıldığ 1 Sharma ve ark. çalışmasında ise, histeroskopi ve endometriyal biyopsi yapılacak hastalar preoperatif analjezik uygulama yolu açısından; oral drotaverin + mefemik asit, paraservikal blok ve intravenöz sedasyon olmak üzere 3 gruba randomize edilmiş, oral drotaverin + mefemik asit kombinasyonu analjezik etkinliği en fazla olan grup olarak bulunmuştur (22).

Biz çalışmamızda endometriyal biyopsi işleminden 30 dakika önce oral yoldan alınan $10 \mathrm{mg}$ HBB'nin, endometriyal biyopsi sırasında ve işlemden 30 dakika sonrasında analjezik etkinliği olduğunu gösterdik. Bu data HBB 'nin diğer jinekolojik endikasyonlar ile kullanımının yaygınlaşmasına yardımcı olabilir. Fakat çalışmamızın retrospektif olarak planlanmış olması, bu nedenle HBB'nin plasebo ile karşılaştıralamaması, olası ilaç yan etkisi datasının dosyalardan edinilememesi çalışmamızın limitasyonlarıdır. HBB'nin tam etki profilini ortaya koyabilmek için randomize, plasebo kontrollü çalışmalara ihtiyaç olduğunu düşünmekteyiz.

\section{KAYNAKLAR}

1. Cooper JM, Erickson ML. Endometrial sampling techniques in the diagnosis of abnormal uterine bleeding. Obstet Gynecol Clin North Am 2000;27:235-44

2. Kazandi M, Okmen F, Ergenoglu AM, Yeniel AO, Zeybek $B$, Zekioglu O, Ozdemir N: Comparison of the success of histopathological diagnosis with dilatation-curettage and Pipelle endometrial sampling. J Obstet Gynaecol 2012;32:790-794.

3. Demirkiran F, Yavuz E, Erenel H, Bese T, Arvas M, Sanioglu C: Which is the best technique for endometrial sampling? Aspiration (Pipelle) versus dilatation and curettage (D\&C). Arch Gynecol Obstet 2012;286:1277- 1282.

4. Dogan E, Celiloglu M, Sarihan E, Demir A: Anesthetic effect of intrauterine lidocaine plus naproxen sodium in endometrial biopsy. Obstet Gynecol 2004;103:347-351.

5. Einarsson JI, Henao G, Young AE. Topical Analgesia for Endometrial Biopsy. Obstet Gynecol. 2005 Jul;106(1):128-30.

6. Hui SK, Lee L, Ong C, Yu V, Ho LC: Intrauterine lignocaine as an anaesthetic during endometrial sampling: a randomised double-blind controlled trial. BJOG 2006;113:53-57.

7. Acmaz G, Bayraktar E, Aksoy H, et al. Effect of paracetamol, dexketoprofen trometamol, lidocaine spray, pethidine and diclofenac sodium application for pain relief during fractional curettage: a randomized controlled trial. Indian J Med Res 2015; 142:399-404
8. Kirim S, Asicioglu O, Yenigul N, Aydogan B, Bahat N, Bayrak M. Effect of intravenous hyoscine- $N$-butyl bromide on active phase of labor progress: a randomized double blind placebo controlled trial. J Matern Fetal Neonatal Med. 2015;28(9):1038-1042.

9. Sirohiwal D, Dahiya $K$, De $M$. Efficacy of hyoscine-n-butyl bromide (Buscopan) suppositories as a cervical spasmolytic agent in labour. Aust N Z J Obstet Gynaecol. 2005 Apr;45(2):128-9.

10. Abbas AM, Abo-Elela NA, Mosa EM. Effect of oral hyoscine-Nbutyl bromide on pain perception during hysterosalpingography: A randomized, double-blind, placebo controlled trial. Middle East Fertil Soc J. 2018;23(1):57-62.

11. Jareethum R, Suksompong S, Petyim S, Prechapanich $J$, Laokirkkiat P, Choavaratana R. Efficacy of mefenamic acid and hyoscine for pain Med J Islam Repub Iran. 2019 (16 Apr); 33.31 .

12. Safi F, Kamali A, Rezaei M, Rezaei M, Rafiei M. Effect of intramuscular hyoscine-n-butyl bromide on fallopian tube spasm and pain perception during and after hysterosalpingography in infertile women: A randomized single-blind controlled clinical trial. Med J Islam Repub Iran. 2019 Apr 16;33:31.

13. Abbas AM, Samy A, El-Naser Abd El-Gaber Ali A et al. Medications for pain relief in outpatient endometrial sampling or biopsy: a systematic review and network meta-analysis. Fertil Steril. 2019 Jul;112(1):140-148.e12.

14. Ouladsahebmadarek E, Gharabaghi PM, Behjati F, Azadi A, Seidhejazie M. Role of local anesthetics on pain relief in endometrial biopsy: randomized clinical trial. Int $J$ Women's Health Reprod Sci 2014;2:58-66.

15. Aksoy H, Aksoy U, Ozyurt S, Ac $€$, maz G, Babayigit M. Lidocaine $10 \%$ spray to the cervix reduces pain during intrauterine device insertion: a double-blind randomised controlled trial. J Fam Plann Reprod Health Care 2016;42:83-7

16. Korsuwan P, Wiriyasirivaj B. Lidocaine spray for pain control during office-based endometrial biopsy: a randomized placebo-controlled trial. Thai J Obstet Gynacol 2018;26:46-53.

17. Trolice MP, Fishburne C, McGrady S. Anesthetic efficacy of intrauterine lidocaine for endometrial biopsy: a randomized double-masked trial. Obstet Gynecol 2000;95:345-7.

18. Cengiz H, Dağdeviren H, Kaya C, Ye, sil A, C, aypinar SS. Comparing the efficacy of intrauterine lidocaine and paracervical block in decreasing the pain associated with endometrial biopsy: a randomised trial. Arch Gynecol Obstet 2014;289:609-14.

19. Poomtavorn Y, Phupong V: Prospective randomized, double-blinded, placebo-controlled trial of preoperative rofecoxib for pain relief in uterine curettage. Arch Gynecol Obstet $2005 ; 273: 115-118$

20. Phittayawechwiwat W, Thanantaseth C, Ayudhya NI, $O$-Prasertsawat P, Kongprasert J: Oral etoricoxib for pain relief during fractional curettage: a randomized controlled trial. J Med Assoc Thai 2007;90:1053-1057.

21. Manyou B, Phupong V: Prospective randomized, double-blinded, placebo-controlled trial of preoperative etoricoxib for pain relief in uterine fractional curettage under paracervical block. Eur J Obstet Gynecol Reprod Biol 2008;140:90-94.

22. Sharma JB, Aruna J, Kumar P. Comparison of efficacy of oral drotaverine plus mefenamic acid with paracervical block and with intravenous sedation for pain relief during hysteroscopy and endometrial biopsy. Indian J Med Sci. 2009 Jun;63(6):244-52. 